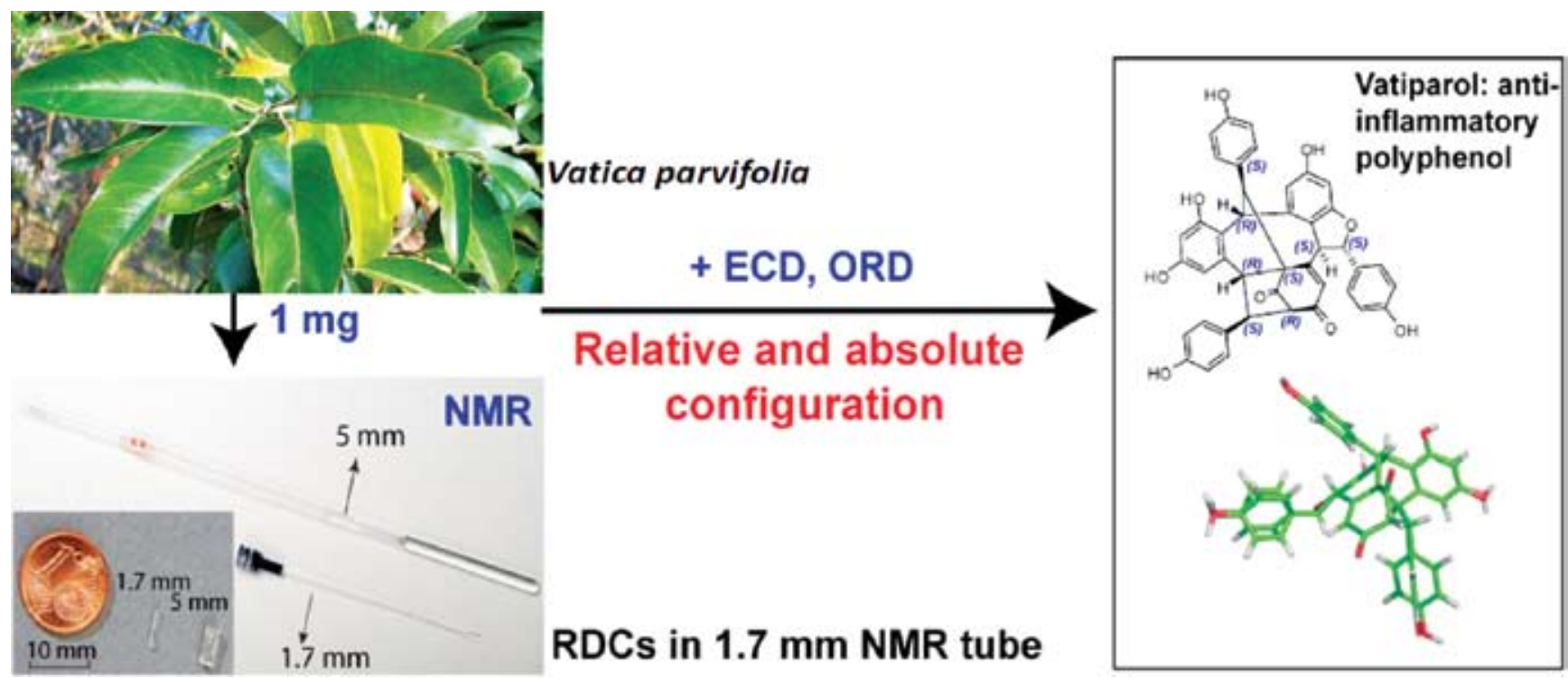

Figure. Structure determination of vatiparol. (ORD, optical rotatory dispersion; ECD, electronic circular dichroism)

\title{
CRUDE AND ETHANOL EXTRACTS OF PROPOLIS AS NATURAL GROWTH PROMOTERS (NGPS) IN MEAT POULTRY PRODUCTION
}

\section{(c) Gheisari Abbasali ${ }^{1}$, Ghalamkari Gholamreza ${ }^{1}$, Amini Hamid Reza $^{2}$, Shahrvand Shekofa ${ }^{2}$, Rezayat Ehsan ${ }^{2}$, Mohammadrezaei Mohammad $^{2}$}

${ }^{1}$ Department of Animal Science, Khorasgan Branch, Islamic Azad University, Isfahan, Iran ${ }^{2}$ Young Researchers Club, Khorasgan Branch, Islamic Azad University, Isfahan, Iran

This study was conducted to evaluate the effects of feeding different levels and sources of propolis substituted for Flavophospholipol as an antibiotic growth promoter on performance of broiler chickens in a completely randomized design. Five hundred and twenty days old broiler chicks (Ross 308) were divided into 40 experimental units of 13 chicks each. Each 4 groups were allocated to one of the ten dietary treatments, randomly. Dietary treatments were included control diet, diet containing $500 \mathrm{mg} / \mathrm{kg}$ of antibiotic Flavophospholipol, 4 diets containing different levels of 50, 100, 200 and $300 \mathrm{mg} / \mathrm{kg}$ ethanol extracts of propolis (EEP) and 4 diets containing 250, 500, 1000 and $2000 \mathrm{mg} / \mathrm{kg}$ of crude propolis. The Indices of performance were evaluated for each treatment during the experimental period (0-42 d of age). The results showed that daily weight gain and feed conversion ratio had no significantly affected by different dietary levels and sources of propolis compared to chickens fed antibiotic Flavophospholipol. The highest averages of body weight at $42 \mathrm{~d}$ of age $(2284 \mathrm{~g})$ and feed intake in total experimental period ( $100.4 \mathrm{~g} / \mathrm{bird} / \mathrm{d}$ ) assigned to chickens fed diet containing $100 \mathrm{mg} / \mathrm{kg}$ EEP. Totally, the results of this experiment showed that, similar to diet containing antibiotic growth promoter, feeding diets supplemented with $100 \mathrm{mg} / \mathrm{kg}$ EEP or $500 \mathrm{mg} / \mathrm{kg}$ crude propolis can improve performance of broiler chicks compared to control diet.

\section{LIFE WITH LARCH - ISOLATED ARABINOGALACTANS AND THEIR IMMUNOLOGICAL ACTIVITIES}

\section{(C) Göllner E. M.}

Pharmaceutical Institute, Department of Pharmaceutical Biology, University of Kiel, Gutenbergstra e 76, 24118 Kiel, Germany

The macromolecular larch arabinogalactan (LAG) is a highly branched polysaccharide consisting of a 1,3-linked galactan backbone with side-chains of 1,6-linked galactose and arabinose residues (1). LAG is an excellent source of dietary fiber and has been approved as such by the US Food and Drug 